ISSN: 2178-7514
ARTIGO ORIGINAL

\section{A IMPORTÂNCIA DA ERGONOMIA NA PRÁTICA DO EXERCÍCIO FÍSICO NA ACADEMIA}

The importance of ergonomics in the practice of physical exercise in the academy

Aline Lillian Pereira Simião; Jussara Ferreira de Assis; Rafael dos Santos Andrade; Vinicius Aparecido Galindo; Josinei Leandra Valeretto; Selma Fernandes

Vol. 13 | No. 3| Ano 2021

\title{
RESUMO
}

O objetivo principal deste estudo foi investigar a importância da ergonomia na prática do exercício físico demonstrando o uso certo e errado de equipamentos e acessórios de ginástica numa academia. Neste trabalho, realizou-se pesquisa bibliográfica por meio de artigos, livros e periódicos eletrônicos e de campo, através da coleta de imagens dos sujeitos realizando os movimentos numa academia. Neste artigo destaca-se o quanto é essencial a prática de exercício físico na vida das pessoas para melhoria da sua saúde e qualidade de vida. Na sequência é apresentado o conceito de ergonomia, quais são os seus objetivos e o quão se faz fundamental para os profissionais de educação física seu conhecimento. Além disso, é demonstrado a prática do exercício físico no uso certo e errado de equipamentos e acessórios de ginástica, sendo realizada uma descrição utilizando fotografias que foram feitas pelos autores em uma academia, de exercícios praticados erroneamente em paralelo aos exercícios feitos corretamente. Portanto o profissional que possui o conhecimento em ergonomia orientará um treinamento com segurança para que o indivíduo que pratica, alcançando seus objetivos sem riscos de lesões, evitando quaisquer tipos de transtorno físico ou mental.

Palavras-chave: Ergonomia; Exercício Físico; Aparelhos de Ginástica; Academias.

\begin{abstract}
The main objective of this study was to investigate the importance of ergonomics in the practice of physical exercise, demonstrating the right and wrong use of gym equipment and accessories in a gym. In this work, a bibliographical research was carried out through articles, books and electronic and field periodicals, through the collection of images of the subjects performing the movements in an academy. This article highlights how essential the practice of physical exercise is in people's lives to improve their health and quality of life. Next, the concept of ergonomics is presented, what are its goals and how fundamental it is for physical education professionals to have their knowledge. In addition, the practice of physical exercise in the right and wrong use of gym equipment and accessories is demonstrated, and a description is made using photographs that were taken by the authors in a gym, of exercises performed wrongly in parallel to exercises performed correctly. Therefore, the professional who has knowledge in ergonomics will guide training safely for the individual who practices, reaching their goals without risk of injury, avoiding any type of physical or mental disorder.
\end{abstract}

Keywords: Ergonomics; Physical Exercise; Gym Equipment; Academies. 


\section{INTRODUÇÃO}

A atividade física é essencial para a vida de qualquer pessoa, pois por meio de exercícios físicos diários o indivíduo terá uma boa saúde. A ciência já provou que uma pessoa que pratica exercícios diariamente evita várias doenças no futuro, principalmente as doenças cardiovasculares, como por exemplo: o infarto e a hipertensão arterial. Além disso, outras doenças podem ser evitadas como: o acidente vascular cerebral (AVC), popularmente chamado de derrame. As dores lombares, diabetes tipo 2, obesidade e até câncer podem ser prevenidos com a prática de exercícios físicos diários ${ }^{(1)}$.

Houve uma época em que fazer atividade física era sinônimo de sobrevivência, pois o homem precisava correr de feras, caçar e $\operatorname{plantar}^{(2)}$.

A população no mundo está vivendo cada vez mais e com o avanço da medicina visando a melhoria da saúde e qualidade de vida do sujeito, com o intuito de desenvolver novas formas de minimizar e tratar doenças, contribuindo no aumento da longevidade do ser humano. Para atingir esta melhoria na qualidade de vida, pode-se pensar em atividade física, que é essencial para a manutenção e preservação da capacidade funcional das pessoas, podendo mantê-las independentes em suas tarefas cotidianas durante toda a vida ${ }^{(3)}$.
Além de trazer ganhos à saúde do corpo, a atividade física pode beneficiar a saúde mental, trazendo mais disposição, não apenas física, mas no bem-estar do indivíduo, confiança para as atividades diárias e para o relacionamento com as pessoas. No entanto, para atingir tais objetivos é necessário a existência de espaços públicos ou privados que contemplem todo tipo de pessoas, e as academias de ginástica são a solução ${ }^{(4)}$.

Está comprovado que praticar atividade física é um fator de proteção para diversos problemas de saúde, além de promover bemestar físico e psicossocial e melhorar a saúde e qualidade de vida dos praticantes. Apesar do conhecimento científico acumulado sobre os benefícios da prática regular de atividade física, o fato de ser fisicamente ativo ainda não é um hábito comum à população mundial ${ }^{(5)}$.

Atualmente houve um aumento significativo da popularização das academias de ginástica e da prática de exercício físico. As academias estão se adaptando e modernizando, mas principalmente investindo em novos equipamentos para atrair e manter seus clientes. Desta forma, as academias se adaptam as necessidades ergonômicas buscando conforto, usabilidade e eficiência nos resultados ${ }^{(4)}$.

$\mathrm{Na}$ pré-história, o homem não tinha nada além do próprio corpo para ajudá-lo em sua atividade física, hoje ele tem a ajuda de equipamentos e máquinas para facilitar sua prática na rotina diária de exercícios físicos. 
O uso de anilhas, halteres e máquinas de levantamento de pesos são ferramentas do homem contemporâneo e atrelado a isto está a ergonomia ${ }^{(6)}$.

A ergonomia é uma ciência que tem como objetivo adaptar e estruturar objetos e espaços para que pessoas os utilizem de forma eficiente e com segurança. Esse termo é muito comum ao se falar em conforto e bem-estar das pessoas. As academias precisam atentar ao funcionamento dos aparelhos, que necessitam de manutenções e $\operatorname{reparos}^{(7)}$.

A organização dos itens de uma academia é muito importante, pois a disposição sem planejamento dos instrumentos de academia, como por exemplo, os halteres, pode causar acidente grave. Assim sendo, os aparelhos precisam estar bem-posicionados e encaixados, como também, os frequentadores devem ser orientados para que tenham segurança no momento dos exercícios físicos. A ergonomia é a responsável por isso, desde a disposição dos equipamentos esportivos, sua manutenção e cuidados com as pessoas ${ }^{(3)}$.

A fim de economizar tempo e facilitar o treino dos frequentadores de academia aplica-se a ergonomia, que visa contemplar todo tipo de público, desde pessoas obesas ou com comorbidades a atletas profissionais. Há equipamentos para usuários de pesos e alturas diferentes, pois a tarefa da ergonomia é facilitar e motivar todos à prática do exercício físico. A segurança e o bem-estar das pessoas é o principal objetivo dessa ciência ${ }^{(4)}$.
A Associação Brasileira de Ergonomia, conceitua a Ergonomia como uma disciplina orientada para a abordagem sistêmica de todos os aspectos da atividade humana. A ergonomia tem como objetivo melhorar as condições específicas do trabalho humano, ajudando as pessoas a desempenhar melhor suas atividades, oferecendo conforto, eficácia e segurança para a realização do trabalho. Ela deve ser entendida como um conjunto de princípios e conceitos eficazes para viabilizar as mudanças necessárias para adequação do trabalho às características, habilidades e limitações dos trabalhadores, bem como dos produtos e sistemas, à luz dos critérios da saúde, segurança e efetividade ${ }^{(3)}$.

Ergonomia é uma palavra grega que designa a ciência responsável em estudar as condições de trabalho. Desde a pré-história o homem pesquisa técnicas para facilitar as condições de trabalho humano, mas foi somente no século XX que a palavra foi usada oficialmente. Quando o homem pré-histórico procurava uma forma de construir suas pontas de lanças, já estava fazendo uso da ciência ergonômica. Portanto essa ciência nasceu da necessidade de sobrevivência e de contornar as adversidades expostas pela vida primitiva ${ }^{(8)}$.

A visão ergonômica se estende aos aspectos físicos e mentais, tendo como foco o ser humano e a melhoria na sua vida cotidiana, observando as várias situações de trabalho, pois na maioria das vezes as condições de segurança, conforto e saúde são negligenciadas ${ }^{(9)}$. 
A ergonomia surgiu para descomplicar as tarefas diárias. Ela está sempre adaptando a tarefa ao homem e nunca o contrário. Por exemplo, os comandos, botões e assentos de um automóvel são objeto de muito estudo para que estes se tornem confortáveis e cumpram com o seu objetivo. Estes dispositivos são contribuições ergonômicas ${ }^{(8)}$.

A função dos ergonomistas é projetar ou redesenhar máquinas, equipamentos, instrumentos e ferramentas laborais, tentando diminuir os constrangimentos provocados pela exposição do homem aos postos de trabalho, e assim buscar por melhorias nas condições de trabalho do homem e minimização de problemas provocados na execução da tarefa (10).

O objetivo deste estudo é investigar a importância da ergonomia na prática de exercício físico demonstrando a utilização correta e equivocada dos equipamentos e acessórios de ginástica na academia.

\section{MATERIAIS E MÉTODOS}

Este estudo compreende duas etapas: pesquisa bibliográfica e de campo. No levantamento bibliográfico foi realizado uma revisão integrativa da literatura, buscando artigos em ambiente virtual como SciELO (Scientific Eletronic Library Online), Google Acadêmico, Pubmed, nas áreas de Educação Física e Ergonomia.
A pesquisa bibliográfica foi realizada no período de junho de 2021 a outubro de 2021, a partir das obras relativas aos termos chave do trabalho, relacionados entre si (Ergonomia, Exercício Físico, Equipamentos de Ginástica, Academia). No levantamento bibliográfico, foram consideradas as seguintes formas de análise ${ }^{(11)}$.

- análise textual: busca as principais ideias do autor, seu estilo e método de escrita.

- análise temática: visa ouvir o autor e observar o problema que o autor está apresentando.

- análise interpretativa: busca interpretar o texto, através das ideias do autor.

- problematização: consiste em debater os problemas existentes no texto para ampliar a discussão.

Já na pesquisa de campo, realizada na segunda etapa, mediante ao objetivo proposto foram coletadas imagens realizadas pelos autores do estudo em uma academia do interior de Minas Gerais, simulando posturas certas e erradas durante a realização dos exercícios físicos nos equipamentos e acessórios de ginástica. Logo após, foram realizadas as descrições dessas posturas e os benefícios de cada exercício executado.

\section{RESULTADO E DISCUSSÃO}

O estudo demonstra as posturas corretas e incorretas dos frequentadores de 
academia durante a realização de exercícios físicos utilizando equipamentos e acessórios de ginástica.
Para identificar a postura errada foi utilizado o símbolo $\bigotimes$ e para identificação da postura certa utilizou-se o símbolo

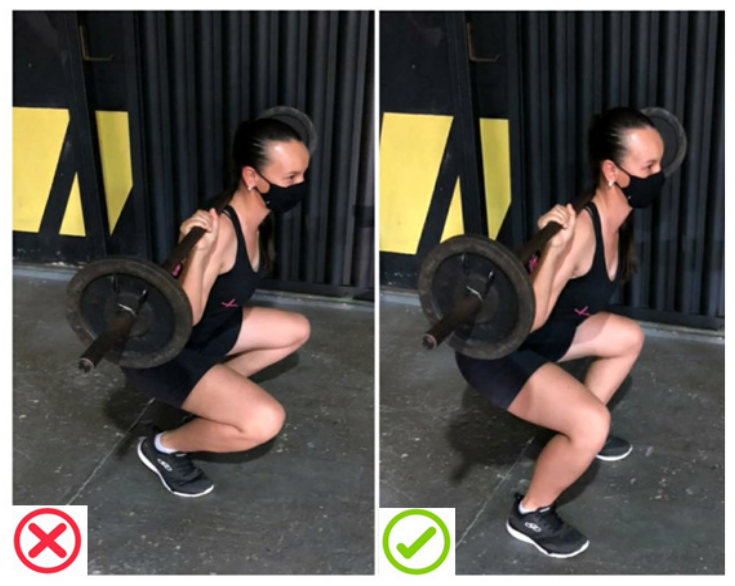

Figura 1 - Agachamento (squat)

$\mathrm{Na}$ figura 1 nota-se o agachamento sendo executado de forma errada, os joelhos passaram da linha dos dedos dos pés, os calcanhares não estão apoiados no chão e o indivíduo passou do limite e agachou demais.

Ainda na figura 1 observa-se $o$ agachamento de forma certa, o indivíduo está com a coluna posicionada corretamente, com alinhamento da cabeça acompanhando a postura da coluna e os pés estão apoiados sobre o chão por inteiro. Na dinâmica do movimento deve-se manter a angulação de $90^{\circ}$ dos joelhos ao realizar o movimento de descida.

O agachamento ou squat é uma modalidade de exercício que tem como características estimular a região muscular dos glúteos. O agachamento e suas diversas variações tonificam o quadríceps femoral na região da coxa, trabalham a região abdominal e alongam a musculatura da região do dorso.
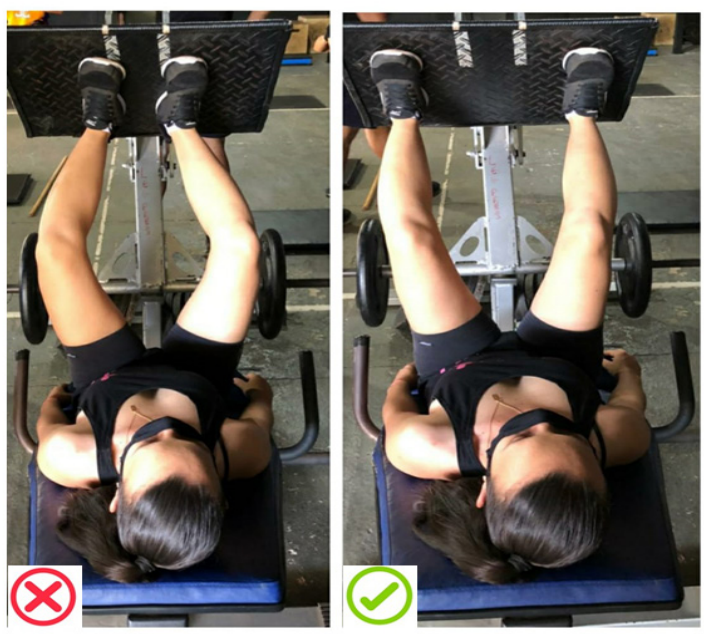

Figura 2 - Leg press 

sendo realizado com a execução equivocada na dinâmica do movimento humano. As articulações dos joelhos não estão alinhadas com os pés, ou seja, os joelhos estão voltados para fora.
$\mathrm{Na}$ figura 2 nota-se o leg press

Nesta mesma figura 2 observa-se o leg press sendo realizado de forma correta, com a coluna apoiada no equipamento e as articulações dos joelhos alinhadas com os pés.

O leg press estimula os membros inferiores, fortalecendo os músculos quadríceps femoral e isquiotibiais, além de enfatizar a região dos glúteos.

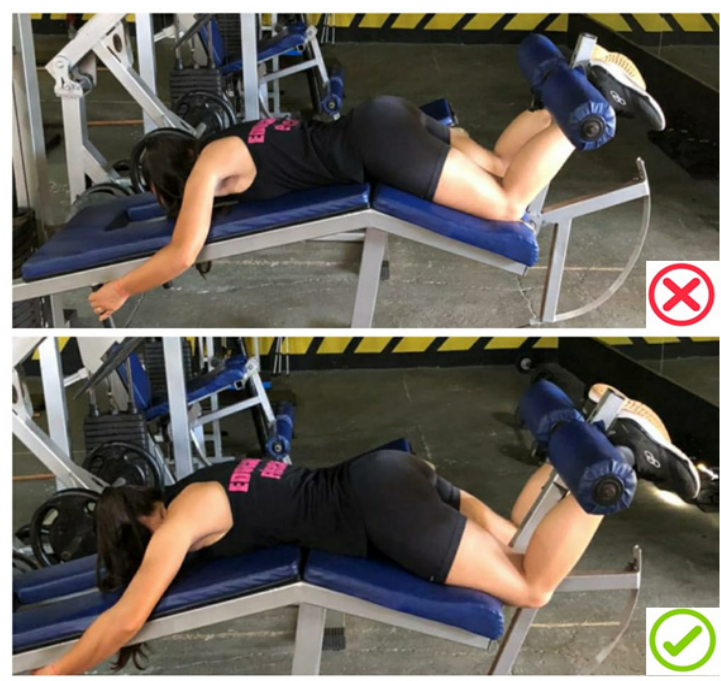

Figura 3 - Mesa flexora

$\mathrm{Na}$ figura 3 nota-se a mesa flexora sendo

Ainda na figura 3 observa-se a mesa realizada de forma errada, o posicionamento flexora sendo realizada de forma certa, os dos joelhos está fora da articulação da joelhos estão alinhados com a movimentação cadeira, ocasionando uma tensão maior nestas articulações. de articulação do equipamento.

A mesa flexora promove $\mathrm{O}$ fortalecimento dos isquiotibiais.

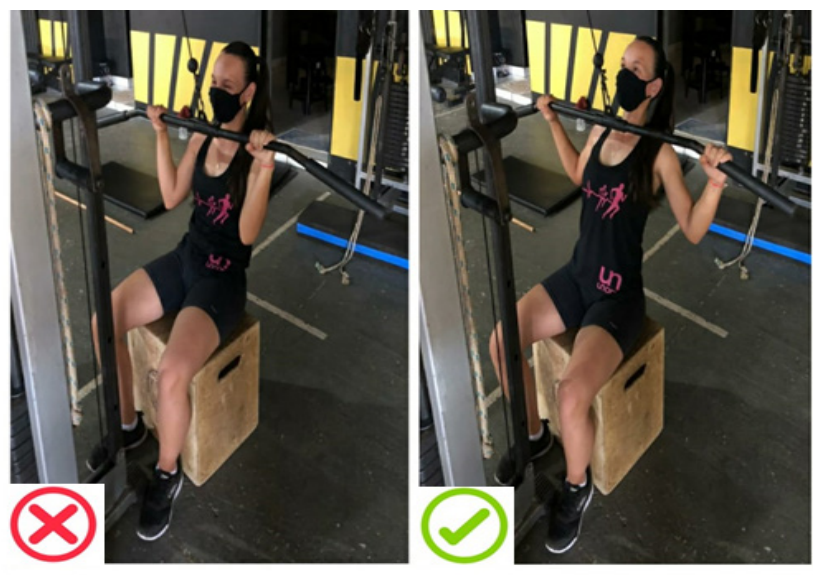

Figura 4 - Pulley frente 
$\mathrm{Na}$ figura 4 nota-se o Pulley frente sendo realizado de forma errada, a pegada das mãos está fechada tendo uma tensão nas articulações dos cotovelos, a posição da cabeça não está alinhada com a coluna, também promovendo uma tensão.

Nesta mesma figura 4 observa-se o Pulley frente sendo realizado de forma certa, a pegada da barra está posicionada de forma correta, sem sofrer uma tensão nas articulações dos cotovelos e a posição da cabeça está alinhada com a coluna.

O Pulley frente fortalece a maior parte da musculatura dorsal, com isso ajuda a manter a postura ereta de forma correta.

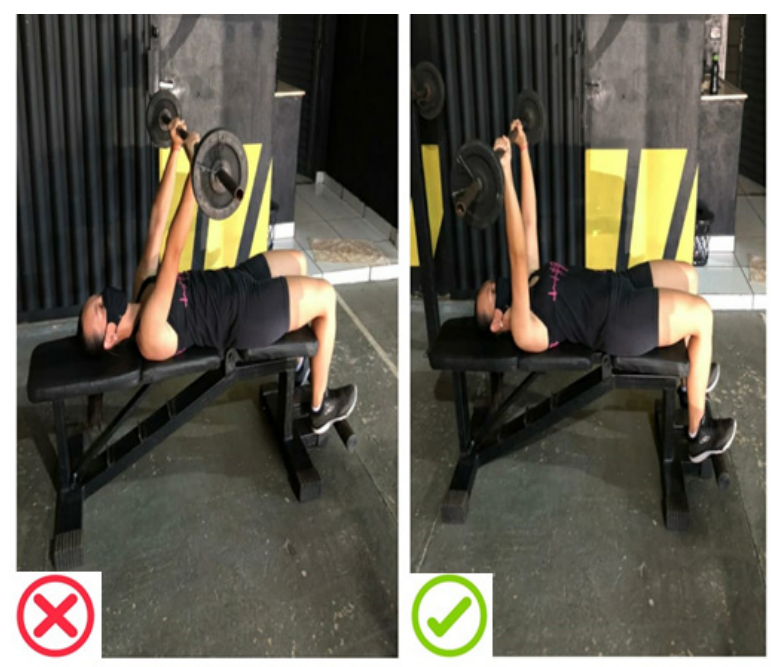

Figura 5 -Tríceps testa

$\mathrm{Na}$ figura 5 pode-se observar o tríceps testa sendo realizado de forma errada, com sobrecarga nos ombros pelo fato da barra não estar alinhada à linha do deltoide.

Ainda na figura 5 nota-se o tríceps testa sendo realizado de forma certa, coluna apoiada no banco e posição da barra alinhada com o deltoide.

O tríceps testa promove o fortalecimento das três cabeças do tríceps braquial por completo.
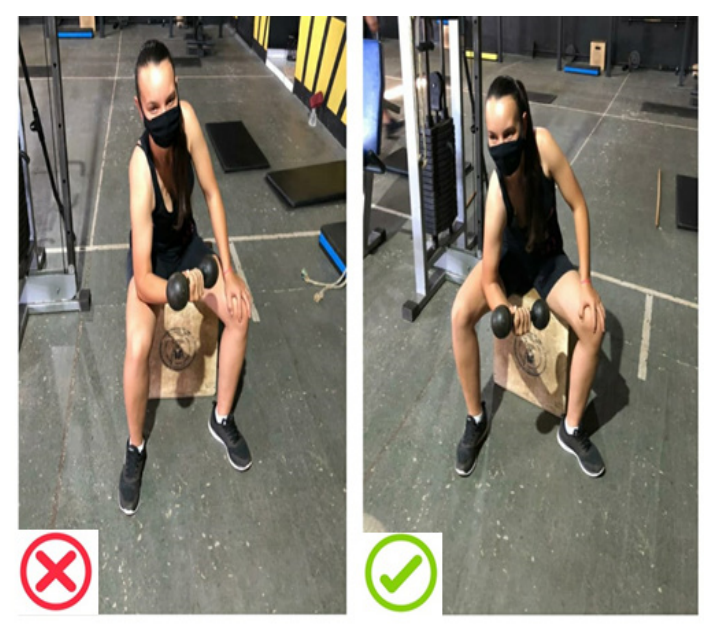

Figura 6 - Rosca concentrada 
$\mathrm{Na}$ figura 6 pode-se observar a rosca concentrada sendo realizada de forma errada, o cotovelo está apoiado no quadríceps femoral, atrapalhando a execução correta do movimento e deixando o peso mais leve.

Nesta mesma figura 6 nota-se a rosca concentrada sendo realizada de forma certa, o corpo alinhado com a execução do movimento e o cotovelo apoiado na face medial da coxa,

dessa maneira, ajuda a melhorar a execução do exercício.

A rosca concentrada fortalece os músculos bíceps braquial, braquial e braquiorradial, com esse exercício permite-se que a carga e a intensidade sejam trabalhadas igualmente nos dois braços, amenizando possíveis diferenças entre eles.

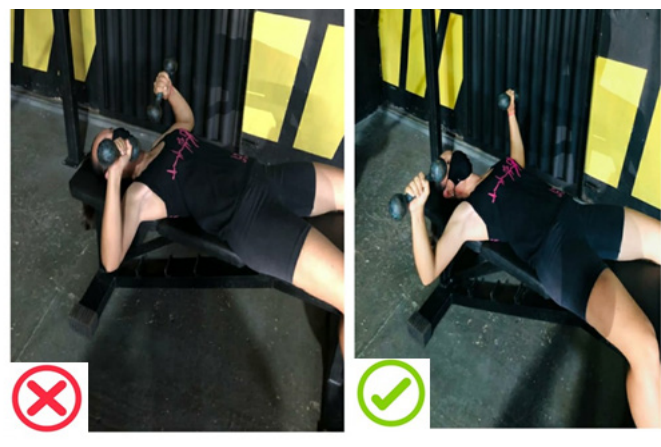

Figura 7 - Supino reto com halteres

$\mathrm{Na}$ figura 7 pode-se observar o supino reto com halteres sendo realizado de forma errada, sobrecarregando as articulações dos cotovelos, estando o ângulo da flexão dos cotovelos fechado.

Ainda na figura 7 nota-se o supino reto com halteres sendo realizado de forma certa, no ângulo correto, sem sobrecarregar as articulações dos cotovelos.
O supino reto com halteres promove o fortalecimento dos músculos peitoral menor e maior. Esse exercício tem como vantagem o equilíbrio muscular, maior amplitude de movimento, liberdade de movimento e permite que a carga e a intensidade sejam trabalhadas igualmente nos dois braços, amenizando possíveis diferenças.

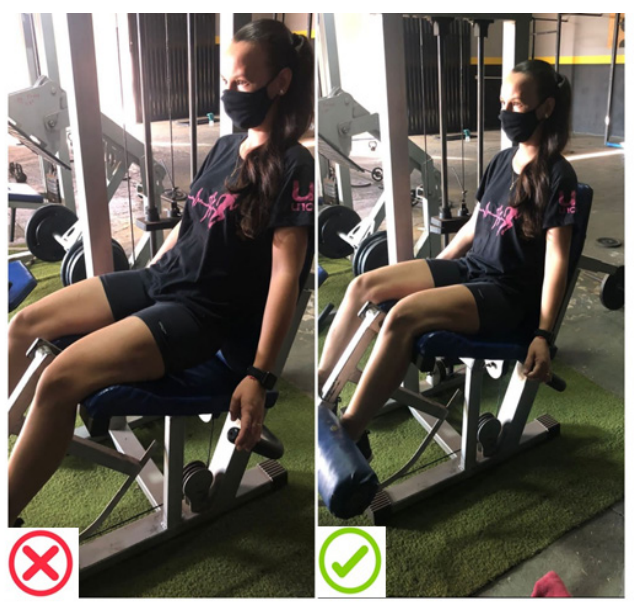

Figura 8 - Cadeira extensora 
$\mathrm{Na}$ figura 8 pode-se observar a cadeira extensora sendo realizada de forma errada, o quadril e a coluna lombar não estão apoiados na cadeira, fazendo com que as articulações dos joelhos fiquem desalinhadas com o movimento de rotação.

Nesta mesma figura 8 nota-se a cadeira extensora sendo realizada de forma certa, o corpo está bem apoiado à mesa segurando o braço de apoio para não deixar o quadril levantar do aparelho.

A cadeira extensora fortalece $\mathrm{O}$ ligamento patelar, isolando a musculatura do quadríceps femoral como reto femoral, vasto lateral, medial e intermédio.

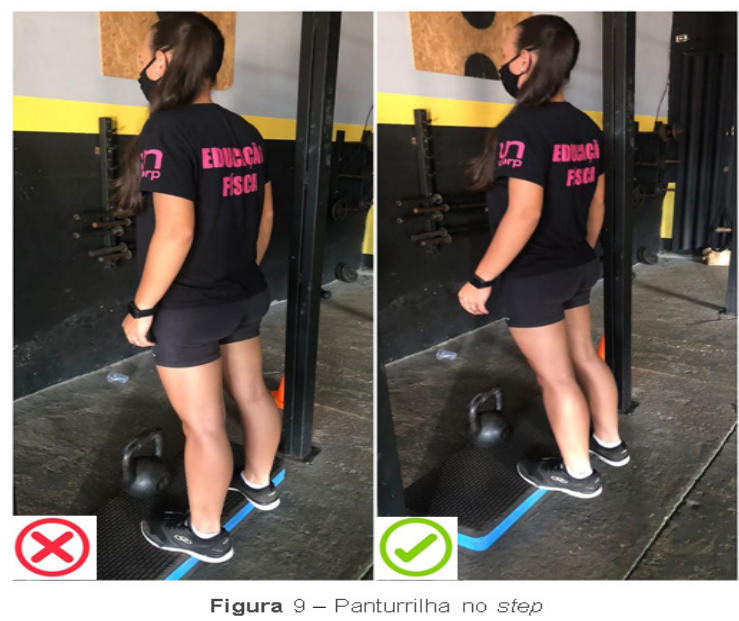

$\mathrm{Na}$ figura 9 pode-se observar a panturrilha no step sendo realizada de forma errada, as plantas dos pés estão quase por completo no step com isso as extensões da musculatura das panturrilhas estão sendo limitadas, deixando a execução curta, pela metade.

Ainda na figura 9 nota-se as panturrilhas no step sendo realizadas de forma certa, os pés estão apoiados corretamente com as pontas dos pés, ocorrendo a extensão correta na amplitude do movimento.

A panturrilha no step além de promover o fortalecimento do calcanhar e dos principais músculos da panturrilha como sóleo e os gastrocnêmios, auxilia na circulação do sangue.

\section{CONCLUSÃO}

A ergonomia passou por diversos estágios de evolução, propondo soluções que acompanhassem os avanços tecnológicos. Desde os primórdios o homem busca um meio que facilite sua vida e a ergonomia foi um desses pilares de apoio, ajudando-o em vários setores da sua vida. E atualmente as academias de ginástica têm seus espaços ergonomicamente planejados como também seus aparelhos passam pelo crivo da ergonomia.

Já é sabido que o exercício físico é importante para melhoria da saúde e qualidade de vida do sujeito, no entanto, se for feito de forma errada, pode acarretar lesões permanentes para a pessoa. E tais lesões podem afetar os gestos motores, as articulações 
e acarretar problemas na coluna.

O profissional de Educação Física é extremamente importante nessa área, pois ele tem o conhecimento para orientar a pessoa a fazer corretamente o uso dos equipamentos de ginástica dia após dia, levando o praticante a realizar o exercício físico de forma consciente e com segurança.

É de responsabilidade do profissional em Educação Física periodizar um treinamento com segurança para que o indivíduo que pratica possa alcançar os seus objetivos sem riscos de lesões, evitando quaisquer tipos de transtorno físico ou mental. O profissional que possui o conhecimento em ergonomia terá uma visão mais cuidadosa em relação aos seus alunos.

Dessa forma, é fundamental que o praticante tenha orientação profissional com qualidade e considere a forma e quantidade de execução dos exercícios para que estes sejam realizados corretamente sem colocar a estrutura corporal em risco, prevenindo-se de qualquer tipo de lesão (dores na coluna, nas articulações), e principalmente, evitando consequências permanentes.

\section{REFERÊNCIAS}

1. JACOB FILHO, Wilson. Atividade física e envelhecimento saudável Wilson. Rev. bras. Educ. Fís. Esp., São Paulo, v.20, p.73-77, set. 2006. Suplemento n.5. http:/ / danielsimonn.com.br/recomendados/terceiraidade/artigo3.pdf. Acesso em 15/07/2021, às 8:30 horas.

2.OLIVEIRA, Vitor Marinho de. O que é Educação Física. São Paulo: Brasiliense, 2004 (Coleção primeiros passos:79).

3.SILVA, Renan Sena de Castro; VELOSO, Isis Tatiane de Barros Macêdo. Equipamentos de ginástica satisfação e caracterização dos usuários. $17^{\circ}$ Ergodesign Congresso Internacional de Ergonomia e Usabilidade de Interfaces Humano Tecnológica: Produto, Informações
Ambientes Construídos e Transporte $17^{\circ}$ USIHC Congresso Internacional de Ergonomia e Usabilidade de Interfaces Humano Computador. Rio de Janeiro. 2019. http://pdf.blucher.com.br.s3-sa-east-1.amazonaws. com/designproceedings/ergodesign2019/2.43.pdf. Acesso em 20/07/2021, às 12:45 horas.

4.CAPINUSSU, José Maurício, Academias de ginástica e condicionamento físico - origens. Atlas do Esporte no Brasil. Rio de Janeiro: CONFEF, 2006. http://www. atlasesportebrasil.org.br/textos/145.pdf. Acesso em 06/09/2021, às 13:59 horas.

5.COSTA, Bruno Gonçalves Galdino da; FREITAS, Cíntia de la Rocha; SILVA, Kelly Samara da. Atividade física e uso de equipamentos entre usuários de duas Academias ao Ar Livre. Costa et al. Rev Bras Ativ Fís Saúde 2016; 21(1):29-38.

6.LÁUAR, Ana Clara Fernandes; LIMA, Marcos José Alves de; LIMA, Verena Ferreira Tidei de; SILVA, José Carlos Plácido da; PASCHOARELLI, Luis Carlos. A origem da ergonomia na Europa: contribuições específicas da Inglaterra e da França. 2010. at: https:/ / www.researchgate.net/publication/282295011. Acesso em 15/07/2021, às 14:55 horas.

7.SILVA, José Carlos Plácido da; PASCHOARELLI, Luis Carlos. A evolução histórica da ergonomia no mundo e seus pioneiros. Editora cultura acadêmica. São Paulo. 2010. https://static.scielo.org/scielobooks/b5b72/pdf/ silva-9788579831201.pdf Acesso em 16/07/2021, às 11:45 horas.

8.IIDA, Itiro. Ergonomia: projeto e produção. 2. ed. Ver. E amp. São Paulo: Blucher, 2005.

9.GRACIOLLI, Lilian Seligman; PAIXÃO, Dinara Xavier da; CONTO, Juliana De; BITENCOURT, Raquel Fava de. Reflexões ergonômicas sobre a voz de professores de academia de ginástica. ENERP XXII Encontro Nacional de Engenharia de Produção. Curitiba. 2002. http://www.abepro.org.br/biblioteca/ enegep2002_tr40_1117.pdf acesso em 15/07/2021, às 13:43 horas.

10.ALMEIDA, Rodrigo Gomes de. A ergonomia sob a ótica anglo-saxônica e a ótica francesa. VÉRTICES, Campos dos Goytacazes/RJ, v. 13, n. 1, p. 115-126, jan./ abr. 2011

11.SEVERINO, Antônio Joaquim. J. Metodologia do trabalho científico. 21. ed. São Paulo: Cortez, 2007.

OBSERVAÇÃO: Os autores declaram não existir conflitos de interesse de qualquer natureza. 